\title{
ANALISIS PENGENDALIAN KUALITAS PRODUK BOS ROTOR PADA PROSES MESIN CNC LATHE DENGAN METODE SEVEN TOOLS
}

\author{
ENDI HARYANTO ${ }^{1)} \&$ IPIN NOVIALIS ${ }^{2)}$ \\ Fakultas Teknik Industri, STTM-Muhammadiyah Tangerang \\ Jl. Syekh Nawawi (Jl Pemda) KM 4 No 13 Matagara, Tigaraksa - Tangerang Banten \\ Email: endiharyanto01@gmail.com ${ }^{1)}$ ipinnovialis@gmail.com ${ }^{2)}$
}

\begin{abstract}
Problems that often occurred on PT X. Mazebah Saroha are significant number of costs from defective products that resulting waste. This study aims to help the company in achieving standard quality that has already been defined and decrease waste from defective products. The method that has been used to increase the quality on PT. $X$ is seven tools. There are 7 analysis tools in seven tools method,: check sheet, scatter diagram, fishbone diagram, pareto diagram, flow chart, histogram, control chart. Flow chart serves to show production flow on PT. X so that the next analysis process can be facilitated. Check sheet and histogram serves to present comprehensive data of defective products based on their type of defects. Control chart scatter diagram serves to show whether some taken variables have connection on each other. Pareto chart serves to show which types of defective product are the most dominant so that some precaution can be done. Fish bone diagram serves to help find the factors that cause the occurrence of defective products.
\end{abstract}

Keywords: Quality, Defect Product, Seven Tools.

\begin{abstract}
ABSTRAK
Masalah yang sering terjadi pada PT X ialah produk cacat yang dapat meningkatkan biaya sehingga terjadi pemborosan. Tujuan dari penelitian ini adalah ini adalah untuk membantu perusahaan dalam mencapai standar kualitas yang sudah ditetapkan dan mengurangi pemborosan yang terjadi karena produk cacat. Metode yang digunakan untuk meningkatkan kualitas pada PT X ialah seven tools. Terdapat 7 alat analisis dalam metode seven tools, yaitu: check sheet, scatter diagram, fishbone diagram, pareto diagram, flow chart, histogram, control chart. Flow chart berfungsi untuk memperlihatkan alur produksi pada PT. X sehingga dapat mempermudah proses analisis selanjutnya. Check sheet dan histogram berfungsi untuk menyajikan data lengkap produk cacat berdasarkan jenis cacatnya. Control chart berfungsi untuk memonitor produk cacat yang keluar dari batas kendali yang sudah ditentukan. Scatter diagram berfungsi untuk memperlihatkan apakah beberapa variabel yang diambil memiliki hubungan. Pareto chart berfungsi untuk dapat memperlihatkan jenis produk cacat mana yang paling dominan sehingga dapat dilakukan tindakan terhadap produk cacat yang dominan tersebut. Fish-bone diagram berfungsi untuk membantu mencari faktorfaktor yang menjadi penyebab terjadinya produk cacat.
\end{abstract}

Kata Kunci: Kualitas, Produk Cacat, Seven Tools

\section{PENDAHULUAN.}

Pada saat ini pelaku bisnis dalam industri di Indonesia menyadari akan semakin ber- ubahnya orientasi pelanggannya terhadap kualitas. Dalam persaingan dunia industri yang semakin ketat, perusahaan harus dapat 
bertahan dan bersaing dengan perusahaan sejenis. Oleh sebab itu, perusahaan harus dapat memenuhi keinginan pelanggan dan berusaha untuk dapat mempertahankan pelanggan. Komitmen dari perusahaan untuk terus mempertahankan kualitas dan keinginan pelanggan adalah dengan diterapkannya berbagai sistem manajemen mutu ISO dalam perusahaan, perusahaan telah mengalami perubahan dalam bidang kualitas. Namun perusahaan tidak dapat berhenti begitu saja karena pada kenyataannya masih terdapat produk yang belum sesuai dengan spesifikasi yang ditetapkan atau produk cacat (defect product). Sejalan dengan kemajuan teknologi, dapat diketahui bahwa konsumen menghadapi lebih banyak alternatif produk dengan harga dan pemasok yang berbeda. Hal ini menjadi sebuah persoalan yang harus diperhatikan perusahaan, terutama dalam hal penentuan pilihan produk yang akan dibeli konsumen. Menurut Kotler, pelanggan selalu mencari nilai yang dianggap paling tinggi dari beberapa produk atau jasa yang ada. Mereka membentuk harapan tentang nilai yang akan diperoleh (value expectation). Berdasarkan nilai tersebut, dapat diukur besarnya tingkat kepuasan yang dimiliki pelanggan. Pada kenyataannya, apabila hasil produksi/barang itu tidak dapat mencapai dengan tepat tujuan untuk apa barang tersebut dimaksudkan atau dipergunakan, ini tidak selalu berarti bahwa konsumen atau pembeli akan membuat keluhan-keluhan kepada produsen. Hal ini terjadi, karena seperti kita ketahui bahwa terdapat rantai distribusi antara konsumen dan produsen yang dapat menghalangi pemindahan informasi atau penyampaian keluhan-keluhan ini. Sehingga apabila tidak terdapat kesesuaian/ kecocokan akan tujuan yang diinginkan dari penggunaan barang tersebut, maka biasanya konsumen atau pembeli akan pindah membeli barang merek lain di pasar.

\section{LANDASAN TEORI}

Sifat khas mutu/kualitas suatu produk yang andal harus multi dimensi karena harus memberi kepuasan dan nilai manfaat yang besar bagi konsumen dengan melalui berbagai cara. Oleh karena itu, sebaiknya setiap produk harus mempunyai ukuran yang mudah dihitung (misalnya berat, luas, isi) agar mudah dicari konsumen sesuai dengan kebutuhannya. Disamping itu, harus ada ukuran yang bersifat kualitatif, seperti warna yang unik dan bentuk yang menarik. Jadi terdapat spesifikasi barang untuk setiap produk, walaupun satu sama lain sangat bervariasi tingkat spesifikasinya. Secara umum, dimensi kualitas menurut Garvin Douglas C. Montgomery, mengidentifikasi delapan dimensi kualitas yang dapat digunakan untuk menganalisis karakteristik kualitas barang. Adapun pengertian kualitas menurut American Society For Quality yang dikutip oleh Hazier \& Render adalah keseluruhan corak dan karakteristik dari produk atau jasa yang berkemampuan untuk memenuhi kebutuhan yang tampak jelas maupun yang tersembunyi. Para ahli yang lainnya yang bisa disebut sebagai para pencetus kualitas juga mempunyai pendapat yang berbeda tentang pengertian kualitas.

1. Kualitas mencakup usaha untuk memenuhi atau melebihi harapan konsumen.

2. Kualitas mencakup produk, tenaga kerja, proses dan lingkungan.

3. Kualitas merupakan kondisi yang selalu berubah (misalnya apa yang dianggap merupakan kualitas saat ini, mungkin dianggap kurang berkualitas pada masa yang akan datang).

Secara umum, dimensi kualitas menurut Garvin Douglas C. Montgomery, mengidentifikasi delapan dimensi kualitas yang dapat digunakan untuk menganalisis karakteristik kualitas barang, yaitu sebagai berikut:

1. Performa (Performance);

2. Keistimewaan (feature);

3. Keandalan (reliability);

4. Konformasi (conformance);

5. Daya tahan (durability);

6. Kemampuan pelayanan (serviceability);

7. Estetika (esthetics); dan

8. Kualitas yang dipersepsikan (perceived quality).

\section{Tujuan Pengendalian Kualitas}

Tujuan dari pengendalian kualitas adalah;

1. Agar produk hasil dari produksi dapat mencapai standar kualitas yang telah ditetapkan;

2. Mengusahakan agar biaya inspeksi dapat menjadi sekecil mungkin;

3. Mengusahakan agar biaya desain dari produk dan proses dengan menggunakan kualitas produksi tertentu dapat menjadi 
sekecil mungkin; dan

4. Mengusahakan agar biaya produksi dapat menjadi serendah mungkin.

Tujuan utama pengendalian kualitas adalah untuk mendapatkan jaminan bahwa kualitas produk atau jasa yang dihasilkan sesuai dengan standar kualitas yang telah ditetapkan dengan mengeluarkan biaya yang ekonomis atau serendah mungkin.

\section{Faktor-faktor Pengendalian Kualitas}

Faktor-faktor yang mempengaruhi pengendalian kualitas adalah;

1. Kemampuan proses;

2. Spesifikasi yang berlaku;

3. Tingkat ketidaksesuaian yang dapat diterima; dan

4. Biaya kualitas.

\section{Langkah-langkah Pengendalian Kualitas}

Pengendalian kualitas harus dilakukan melalui proses yang terus menerus dan berkesinambungan. Proses pengendalian kualitas tersebut dapat dilakukan salah satunya dengan penerapan PDCA (Plan-Do-Check-Action) yang diperkenalkan oleh W. Edwards Deming, seorang pakar kualitas ternama berkebangsaan Amerika Serikat, sehingga siklus ini disebut siklus deming (Deming cycle) deming wheel). Siklus PDCA umumnya digunakan untuk mengetes dan mengimplementasikan perubahan-perubahan untuk memperbaiki kinerja produk, proses atau sistem dimasa yang akan datang. Adapun tahapantahapan dalam siklus PDCA adalah sebagai berikut:

1. Mengembangkan rencana (Plan);

2. Melaksanakan rencana $(D o)$;

3. Memeriksa atau meneliti hasil yang dicapai (Check); dan

4. Melakukan tindakan penyesuaian bila diperoleh (Action).

Untuk melaksanakan pengendalian kualitas, terlebih dahulu perlu dipahami beberapa langkah dalam melaksanakan pengendalian kualitas. Untuk mengimplementasikan perencanaan, pengendalian dan pengembangan kualitas diperlukan langkah-langkah sebagai berikut:

1. Mengidentifikasi karakteristik (atribut kualitas);

2. Menetapkan bagaimana cara mengukur setiap karakteristik;
3. Menetapkan standar kualitas;

4. Menetapkan program inspeksi;

5. Mencari dan memperbaiki penyebab kualitas yang rendah; dan

6. Terus-menerus melakukan perbaikan.

4. Alat Bantu Dalam Pengendalian Kualitas

Pengendalian kualitas secara statistik dengan menggunakan SPC (Statistical Process Control) dan SQC (Statistical Quality Control), mempunyai tujuh alat statistik utama yang dapat digunakan sebagai alat bantu untuk mengendalikan kualitas antara lain: check sheet, histogram, control chart, diagram pareto, diagram sebab akibat, scatter diagram dan diagram proses.

1) Lembar Periksa (Check Sheet)

a. Mempermudah pengumpulan data terutama untuk mengetahui bagaimana suatu masalah terjadi.

b. Mengumpulkan data tentang jenis masalah yang sedang terjadi.

c. Menyusun data secara otomatis sehingga lebih mudah untuk dikumpulkan.

d. Memisahkan antara opini dan fakta.

2) Diagram Sebar (Scatter Diagram)

Scatter diagram atau disebut juga dengan peta korelasi adalah grafik yang menampilkan hubungan antara dua variable, apakah hubungan anatara dua variable tersebut kuat atau tidak yaitu antara faktor proses yang mempengaruhi proses dengan kualitas produk.

\section{3) Diagram Sebab Akibat (Cause and Effect Diagram) \\ Diagram ini disebut juga diagram tulang} ikan (fishbone chart) dan berguna untuk memperlihatkan faktor-faktor utama yang berpengaruh pada kualitas dan mempunyai akibat pada masalah yang kita pelajari. Selain itu lita juga dapat melihat faktor-faktor yang lebih terperinci yang berpengaruh dan mempunyai akibat pada faktor utama tersebut yang dapat kita lihat dari panah-panah yang bentuk tulang ikan pada diagram fishbone tersebut.

Faktor-faktor penyebab utama ini dapat dikelompokan dalam:

a. Material/bahan baku;

b. Machine/mesin;

c. Man/tenaga kerja;

d. Method/metode; dan

e. Environment/lingkungan. 
4) Diagram Pareto (Pareto Analysis) Kegunaan diagram pareto adalah:

a. Menunjukan masalah utama.

b. Menyatakan perbandingan masing-masing persoalan terhadap keseluruhan.

c. Menunjukan tingkat perbaikan setelah tindakan perbaikan pada daerah yang terbatas.

d. Menunjukan perbandingan masing-masing persoalan sebelum dan setelah perbaikan.

5) Diagram Alir/Diagram Proses (Process Flow Chart)

a. Mengumpulkan data, mengimplementasikan data juga merupakan ringkasan visual dari data itu sehingga memudahkan dalam pemahaman.

b. Menunjukan output dari suatu proses.

c. Menunjukan apa yang sedang terjadi dalam situasi tertentu sepanjang waktu.

d. Menunjukan kecenderungan dari data sepanjang waktu.

e. Membandingkan dari data periode yang satu dengan periode lain, juga memeriksa perubahan-perubahan yang terjadi.

6) Histogram

Histogram adalah satu alat yang membantu untuk menentukan variasi dalam proses. Berbentuk diagram batang yang menunjukan tabulasi dari data yang diatur berdasarkan ukurannya.

Manfaat histogram adalah:

a. Memberikan gambaran populasi;

b. Memperlihatkan variabel dalam susunan data;

c. Mengembangkan pengelompokan logis; dan

d. Pola-pola variasi mengungkapkan faktafakta produk tentang proses.

7) Peta Kendali (Control Chart)

Peta kendali adalah suatu alat yang secara grafis digunakan untuk memonitor dan mengevaluasi apakah suatu aktivitas/proses berada dalam pengendalian kualitas secara statistika atau tidak sehingga dapat memecahkan masalah dan menghasilkan perbaikan kualitas.

Manfaat dari peta kendali adalah untuk:

a. Memberikan informasi apakah suatu proses produksi masih berada didalam batas-batas kendali kualitas atau tidak terkendali; b. Memantau proses produksi secara terus menerus agar tetap stabil;

c. Menentukan kemampuan proses (capability process).

d. Mengevaluasi performance pelaksanaan dan kebijaksanaan pelaksanaan proses produksi.

e. Membantu menentukan kriteria batas penerimaan kualitas produk sebelum dipasarkan.

Peta kendali digunakan untuk membantu memdeteksi adanya penyimpangan dengan cara menetapkan batas-batas kendali:

a. Upper Control Limit/batas kendali atas (UCL). Merupakan garis batas untuk suatu penyimpangan yang masih diizinkan.

b. Central Line/garis tengah atau pusat (CL). Merupakan garis yang melambangkan tidak adanya penyimpangan dari karakteristik sample.

c. Lower Control Limit/batas kendali bawah (LCL). Merupakan garis batas bawah untuk suatu penyimpangan dari karakteristik sample.

3. METODE PENELITIAN.

1. Jenis dan Sumber Data

1) Data Primer

Data primer merupakan sumber data penelitian yang diperoleh secara langsung dari sumber aslinya (tidak melalui media perantara) yaitu diperoleh dari hasil observasi terhadap Boss Rotor baik secara visual atau dimensi.

2) Data Sekunder

Data sekunder merupakan data penelitian yang diperoleh peneliti secara tidak langsung melalui media perantara (diperoleh dan dicatat pihak lain).

\section{Teknik Pengumpulan Data}

Teknik pengumpulan data merupakan cara mengumpulkan data yang dibutuhkan untuk menjawab rumusan masalah penelitian.

Dalam penelitian ini menggunakan cara sebagai berikut:

1). Pengamatan (Observasi)

Menurut Indriantoro dan Supomo (2014: 157), observasi yaitu proses pencatatan pola perilaku subyek (orang), atau obyek (benda) dan kejadian sistematik tanpa adanya pertanyaan atau komunikasi dengan individu-individu. 


\section{2). Pencatatan}

Teknik ini digunakan untuk mengumpulkan data sekunder, yaitu dengan mencatat laporan produksi dan laporan cacat PT X, dan lembaga lain yang berkaitan dengan penelitian.

\section{Diagram Alir Penelitian}

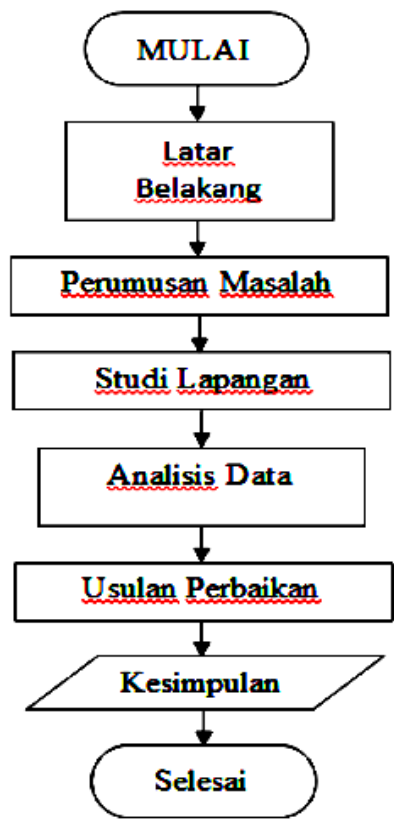

\section{HASIL DAN PEMBAHASAN}

\section{Hasil Penelitian dan Pembahasan}

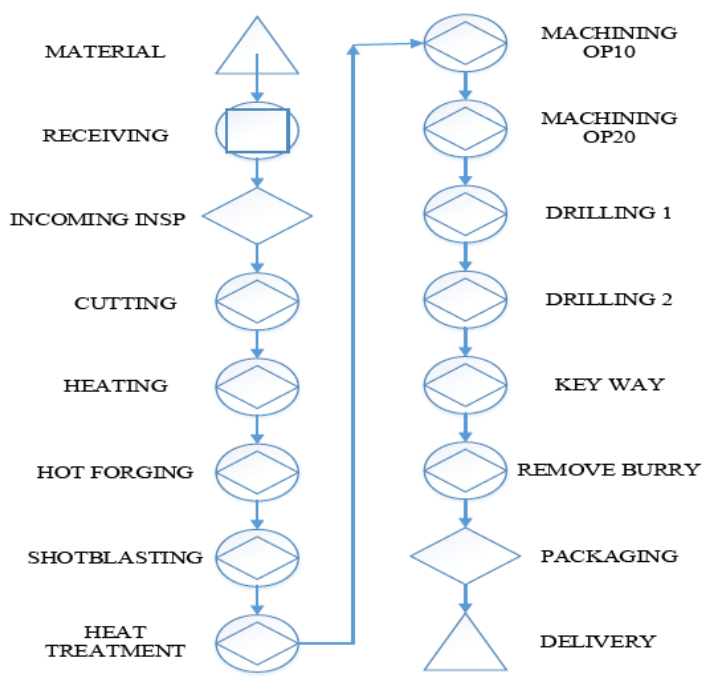

Gambar 4.2 Alur Proses Boss Rotor

\section{1) Lembar Periksa (Check Sheet)}

Langkah pertama yang akan dilakukan dalam pengendalian kualitas secara statistic adalah dengan cara membuat lembar periksa atau check sheet. Fungsi dari lembar periksa adalah untuk mempermudah proses pengum- pulan data serta proses analisisnya.

Tabel 4.1. Data Jumlah Produk Cacat Boss Rotor Tahun 2016

\begin{tabular}{|c|c|c|c|c|c|c|c|c|c|c|c|}
\hline \multirow[b]{3}{*}{ BULAN } & \multirow{3}{*}{ 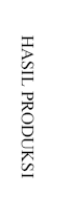 } & \multicolumn{9}{|c|}{ KLASIFIKASI MASALAH } & \multirow{3}{*}{ 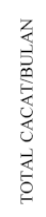 } \\
\hline & & \multicolumn{4}{|c|}{ VISUAL } & \multicolumn{5}{|c|}{ DIMENSI } & \\
\hline & & 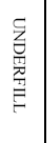 & $\begin{array}{l}\frac{0}{Z} \\
\text { 苟 }\end{array}$ & 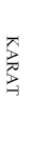 & 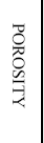 & 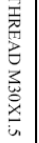 & 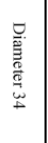 & 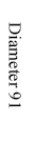 & 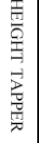 & $\frac{\text { 囬 }}{\bar{z}}$ & \\
\hline JANUARI & 11118 & 318 & 60 & 33 & 108 & 1 & 4 & 9 & 7 & 21 & 561 \\
\hline FEBRUARI & 5864 & 24 & 17 & 1 & 35 & 0 & 9 & 3 & 10 & 22 & 121 \\
\hline MARET & 4469 & 111 & 38 & 3 & 52 & 2 & 19 & 14 & 8 & 65 & 312 \\
\hline APRIL & 6778 & 139 & 39 & 0 & 63 & 0 & 16 & 9 & 13 & 37 & 316 \\
\hline MEI & 10770 & 134 & 50 & 1 & 37 & 13 & 59 & 66 & 22 & 110 & 492 \\
\hline JUNI & 9193 & 11 & 65 & 0 & 10 & 0 & 16 & 8 & 9 & 7 & 126 \\
\hline JULI & 1923 & 15 & 22 & 0 & 2 & 0 & 13 & 0 & 7 & 7 & 66 \\
\hline AGUSTUS & 8930 & 24 & 13 & 12 & 25 & 4 & 5 & 10 & 12 & 3 & 108 \\
\hline SEPTEMBER & 2475 & 4 & 12 & 0 & 19 & 0 & 1 & 1 & 0 & 5 & 42 \\
\hline OKTOBER & 16951 & 26 & 34 & 0 & 21 & 7 & 7 & 7 & 1 & 15 & 118 \\
\hline NOPEMBER & 9420 & 44 & 28 & 1 & 8 & 0 & 50 & 14 & 8 & 23 & 176 \\
\hline DESEMBER & 7709 & 10 & 14 & 2 & 14 & 0 & 19 & 11 & 2 & 3 & 75 \\
\hline TOTAL & 95600 & 860 & 392 & 53 & 394 & 27 & 218 & 152 & 99 & 318 & 2513 \\
\hline
\end{tabular}

Berdasarkan uraian data diatas, terdapat beberapa tipe jenis cacat produk boss rotor pada proses produksi. Berikut adalah penjelasan jenis-jenis cacat yang terdapat pada tabel data diatas;

a. Underfill

Underfill adalah jenis cacat tidak terkupas atau tidak bisa terproses sempurna suatu bagian produk yang yang terjadi pada proses machining disebabkan oleh kondisi dimana produk tidak terisi sempurna saat pembentukan pada proses hot forging.

b. Dented

Dented adalah produk yang dihasilkan terdapat luka pada saat proses produksi berlangsung.

c. Karat

Karat adalah produk yang dihasilkan terdapat karat pada bagian permukaan produk.

d. Porositas (Porosity)

Porositas (Porosity) adalah terdapatnya ruang atau pori-pori yang kecil pada produk.

e. $\quad$ Thread M30x1.5

Cacat thread M30x1.5 yaitu cacat dimana hasil ulir dari produk yang dihasilkan tidak masuk standard yang telah ditetapkan yaitu dengan menggunakan alat inspeksi plunge gauge M30x1.5.

f. $\quad$ Cacat $\emptyset 34$

Cacat $\varnothing 34$ adalah cacat dimana pada poin pengukuruan dimensi $\varnothing 34$ diluar standard dimensi, yang memiliki toleransi plus $0 \mathrm{~mm}$ dan minus $0.05 \mathrm{~mm}$. Pengecekkan poin pengukuran ini meng- 
gunakan micrometer dan juga jig.

\section{g. Cacat $\varnothing 91$}

Cacat $\varnothing 91$ adalah cacat dimensi pada poin pengukuran dimensi $\varnothing 91.015 \mathrm{~mm}$, yang memiliki toleransi batas maksimum diangka $91.054 \mathrm{~mm}$ dan minimum $91.015 \mathrm{~mm}$. Pengecekkan poin pengukuran ini menggunakan air micro dan jig.

8. Cacat Height Tapper

Cacat Height Tapper adalah cacat dari ketinggian tapper pada proses inside diameter pada produk, yang memiliki standard dimensi pengecekkan menggunakan dial indicator.

\section{Cacat Setting}

Cacat setting adalah cacat yang disebabkan proses pada saat melakukan setting awal pada awal shift atau juga pada saat pergantian tooling baru.

\section{2) Diagram Pareto}

Berdasarkan hasil pengamatan dari bulan Januari 2016 sampai dengan bulan Desember 2016 bahwa produk cacat yang ditampilkan pada diagram pareto berikut ini:

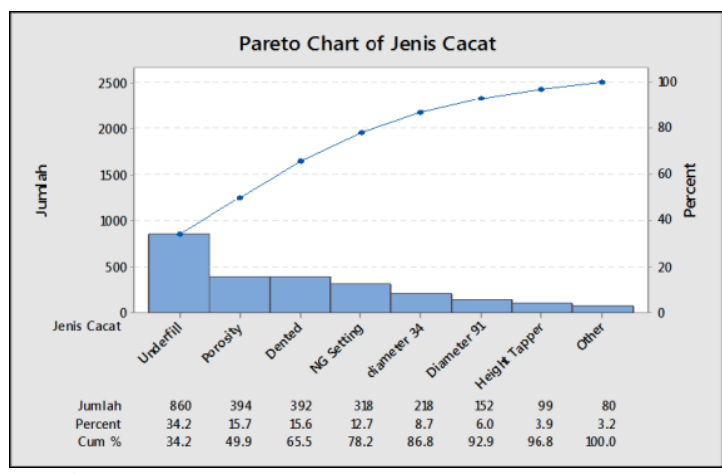

Gambar 4.1. Diagram Pareto

\section{3) Diagram Sebab Akibat (Fishbone)}

Dari pengamatan yang dilakukan dapat diketahui bahwa jenis cacat yang paling dominan pada cacat produk rotor karena underfil. Penyebab terjadinya cacat kerena underfill disebabkan karena adanya beberapa faktor yaitu faktor manusia, faktor material, faktor mesin, faktor metode dan juga faktor metode kerja. Cacat underfill ini terjadi karena tidak adanya fasilitas mesin karena kurangnya perawatan, tidak ada kontrol priodik, tidak ada penggantian tooling, begitu juga faktor dari manusianya kurang teliti pada saat bekerja, kurang peduli terhadap kualitas, dan kurangnya keahlian atau skill operator, dilihat faktor dari material yaitu Hasil proses Forging tidak stabil dan Materoial tidak sesuai.

Tabel 4.2 Faktor yang Diamati dan Masalah yang Terjadi

\begin{tabular}{|c|l|l|}
\hline No. & Faktor yang diamati & \multicolumn{1}{|c|}{ Masalah } \\
\hline 1 & Manusia (Man) & $\begin{array}{l}\text { a. Kurang teliti } \\
\text { b. Kurang peduli kualitas } \\
\text { c. Keahlian/skill }\end{array}$ \\
\hline 2 & Material & $\begin{array}{l}\text { a. Hasil Forging tidak stabil } \\
\text { b. Material tidak sesuai spek }\end{array}$ \\
\hline 3 & Metode (Method) & $\begin{array}{l}\text { a. Mengejar target produksi } \\
\text { b. Intruksi kerja tidak jelas }\end{array}$ \\
\hline 4 & Mesin (Machine) & $\begin{array}{l}\text { a. Kurang perawatan } \\
\text { b. Tidak ada kontrol periodik } \\
\text { c. Pergantian tooling }\end{array}$ \\
\hline 5 & $\begin{array}{l}\text { Lingkungan } \\
\text { (Environment) }\end{array}$ & a. Kebersihan area penyimpanan \\
\hline
\end{tabular}

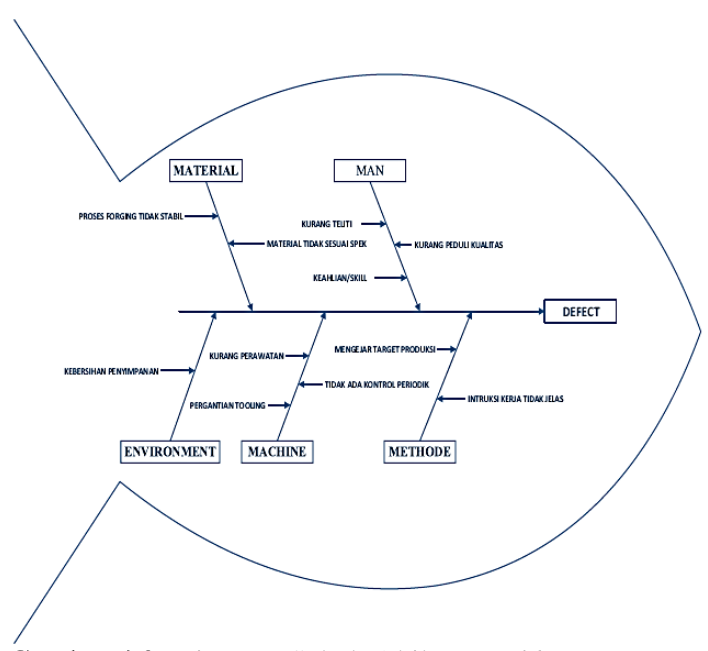

Gambar 4.2. Diagram Sebab Akibat (Fishbone)

\section{4) Faktor Mesin (Machine)}

Mesin merupakan faktor penunjang dalam melakukan kegiatan proses produksi di perusahaan. Peran mesin ini dapat membantu melakukan pekerjaan sehingga pekerjaan tersebut dapat diselesakan dengan cepat dan lebih akurat

\section{Faktor Metode (Methode)}

a. Intruksi kerja tidak jelas

b. Mengejar target produksi

5) Faktor Lingkungan (Environment)

Kebersihan penyimpanan: Kondisi penyimpanan yang kurang bersih dan layak dapat mengakibatkan kecacatan pada produk, seperti contohnya cacat yang terjadi adalah karat yang diakibatkan dari kondisi penyimpanan yang kotor.

6) Diagram Sebar (Sactter Diagram)

Dari banyaknya unit produk yang mengalami cacat dan banyaknya jumlah produksi yang dinyatakan dalam $X$ (produk cacat) dan Y (hasil produksi) pada tahun 2016 ditampil- 
kan data pada diagram sebar sebagai berikut:

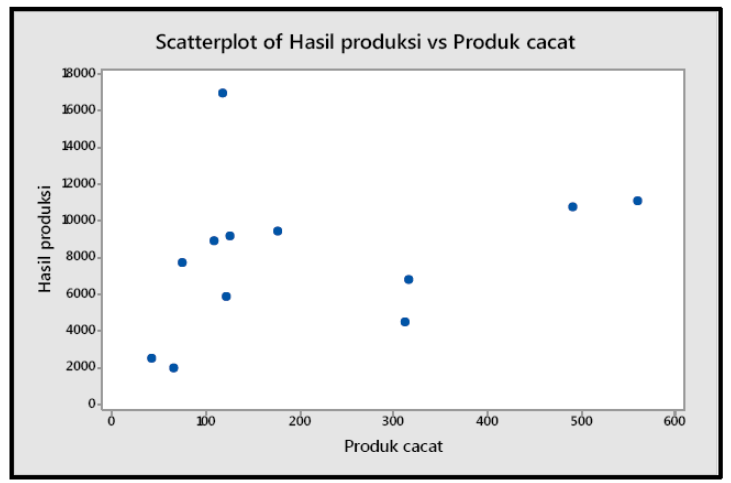

Gambar 4.3. Diagram Sebar (Scatter)

\section{7) Histogram}

Berikut ini adalah histogram untuk data produk cacat Boss Rotor tahun 2016 untuk melihat lebih jelas produk cacat yang terjadi dalam satu periode.

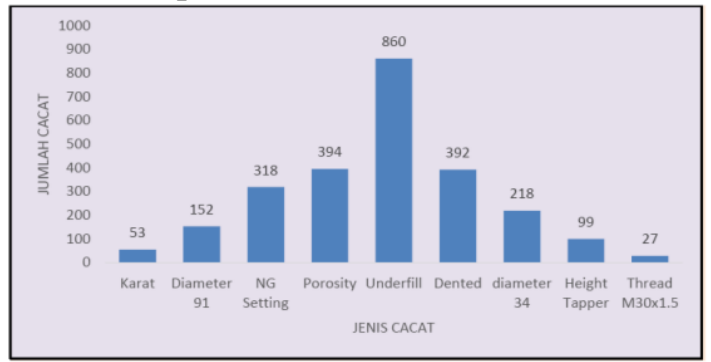

Gambar 4.4. Histogram Produk Cacat Boss Rotor Tahun 2016

\section{8) Peta Kendali (Control Chart)}

Setelah melihat hasil dari histogram maka selanjutnya akan dilakukan analisis kembali untuk mengetahui sejauh mana cacat yang terjadi masih dalam batas kendali statistic melalui diagram alir peta kendali $-p$.

Tabel 4.3. Data Jumlah Produk Cacat Boss Rotor Tahun 2016

\begin{tabular}{|l|c|c|c|c|c|c|}
\hline Bulan & $\begin{array}{c}\text { Hasil } \\
\text { produksi }\end{array}$ & $\begin{array}{c}\text { Produk } \\
\text { cacat }\end{array}$ & Proporsi & CL & UCL & LCL \\
\hline Januari & 11118 & 561 & 0.0505 & 0.026 & 0.1643 & -0.1117 \\
\hline Februari & 5864 & 121 & 0.0206 & 0.026 & 0.1640 & -0.1120 \\
\hline Maret & 4469 & 312 & 0.0698 & 0.026 & 0.1640 & -0.1120 \\
\hline April & 6778 & 316 & 0.0466 & 0.026 & 0.1640 & -0.1120 \\
\hline Mei & 10770 & 492 & 0.0457 & 0.026 & 0.1640 & -0.1120 \\
\hline Juni & 9193 & 126 & 0.0137 & 0.026 & 0.1640 & -0.1120 \\
\hline Juli & 1923 & 66 & 0.0343 & 0.026 & 0.1640 & -0.1120 \\
\hline Agustus & 8930 & 108 & 0.0121 & 0.026 & 0.1640 & -0.1120 \\
\hline September & 2475 & 42 & 0.0170 & 0.026 & 0.1640 & -0.1120 \\
\hline Oktober & 16951 & 118 & 0.0070 & 0.026 & 0.1640 & -0.1120 \\
\hline Nopember & 9420 & 176 & 0.0187 & 0.026 & 0.1640 & -0.1120 \\
\hline Desember & 7709 & 75 & 0.0097 & 0.026 & 0.1640 & -0.1120 \\
\hline Total & 95600 & 2513 & 0.3457 & & & \\
\hline
\end{tabular}

Setelah dilakukan perhitungan menggunakan data yang diperoleh dari perusahaan yang pada bulan Januari sampai Desember 2016. Maka didapat hasil perhitungan seperti pada Tabel 4.2. diatas maka dapat dibuat peta kendali - $\overline{\mathrm{u}}$ sebagai berikut:

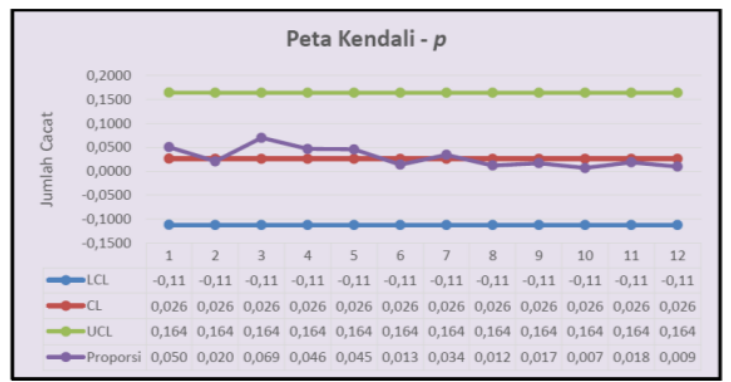

Gambar 4.5. Peta Kendali $-p$

\section{Usulan Perbaikan Kualitas dan Hasil Perbaikan}

1) Usulan Perbaikan

Setelah mengetahui apa saja faktor-faktor penyebabnya produk cacat boss rotor, perusahaan harus mengadakan rapat untuk menanggulangi produk cacat boss rotor supaya tidak terjadi lagi. Berikut adalah usulan perbaikan terkait faktor-faktor penyebab terjadinya produk cacat:

Tabel 4.6. Usulan Perbaikan

\begin{tabular}{|c|c|c|c|}
\hline No. & $\begin{array}{l}\text { Faktor yang } \\
\text { diamati }\end{array}$ & Masalah & Usulan perbaikan \\
\hline \multirow[t]{3}{*}{1} & $\begin{array}{l}\text { Mawusia } \\
\text { (Man) }\end{array}$ & a. Kurang teliti & $\begin{array}{l}\text { kepala regu membantu } \\
\text { mengawasi pada sat proses } \\
\text { produksi }\end{array}$ \\
\hline & & $\begin{array}{l}\text { b. Kurang peduli } \\
\text { kualitas }\end{array}$ & $\begin{array}{l}\text { Departemen QC memberikan } \\
\text { pemalaman teytang kualitas } \\
\text { dan batasan-batasan kualitas } \\
\text { produk. }\end{array}$ \\
\hline & & c. Keablian'skill & $\begin{array}{l}\text { Perusablaan mengadakan } \\
\text { pelatilan kepada operator. }\end{array}$ \\
\hline \multirow[t]{2}{*}{2} & Material & $\begin{array}{l}\text { a. Hasil Forging } \\
\text { tidak stabil }\end{array}$ & $\begin{array}{lcc}\text { Departemen } & \text { QC } & \text { lebih } \\
\text { memperketat kualitas } & \text { pada } \\
\text { proses Hot Forging. } & \end{array}$ \\
\hline & & $\begin{array}{l}\text { b. Material tidak } \\
\text { sesuai spek }\end{array}$ & $\begin{array}{l}\text { melakukan inspeksi terbadap } \\
\text { semua bahan baku yaug } \\
\text { datang. }\end{array}$ \\
\hline \multirow[t]{2}{*}{3} & $\begin{array}{l}\text { Metode } \\
\text { (Method) }\end{array}$ & $\begin{array}{l}\text { a. Mengejar target } \\
\text { produksi }\end{array}$ & $\begin{array}{l}\text { Memberikan target produksi } \\
\text { yang realistis. }\end{array}$ \\
\hline & & $\begin{array}{l}\text { b. Intruksi kerja } \\
\text { tidak jelas }\end{array}$ & $\begin{array}{l}\text { Intruksi kerja ditulis dengan } \\
\text { Iebih terperinci dan dilakukan } \\
\text { training secara rutin. }\end{array}$ \\
\hline \multirow[t]{3}{*}{4} & $\begin{array}{l}\text { Mesin } \\
\text { (Machine) }\end{array}$ & $\begin{array}{l}\text { a. Kurang } \\
\text { perawatan }\end{array}$ & $\begin{array}{l}\text { dilakukan perawatan sesuai } \\
\text { dengan jadwal perawatan. }\end{array}$ \\
\hline & & $\begin{array}{l}\text { b. Tidak ada } \\
\text { koutrol periodik }\end{array}$ & $\begin{array}{lrr}\text { melakukan } & \text { koutrol } & \text { terladap } \\
\text { konmponen } & \text { mesin } & \text { secara } \\
\text { periodik. } & & \end{array}$ \\
\hline & & $\begin{array}{l}\text { c. Pergantian } \\
\text { tooling }\end{array}$ & $\begin{array}{l}\text { mengurangi } \\
\text { pergantian tooling densitas } \\
\text { meningkatkan umur pakai } \\
\text { tooling. }\end{array}$ \\
\hline 5 & $\begin{array}{l}\text { Lingkungan } \\
\text { (Environment) }\end{array}$ & $\begin{array}{l}\text { a. Kebersihan area } \\
\text { penyimpanan }\end{array}$ & $\begin{array}{l}\text { Melaksanakan } 5 S \text { di area } \\
\text { penyimpanan. }\end{array}$ \\
\hline
\end{tabular}

Dari beberapa faktor perbaikan yaitu meliputi dari manusia, material, metode, mesin dan lingkungan, didapat usulan perbaikan yang harus dilakukan guna untuk mengurangi defect atau cacat produk.

\section{2) Hasil Perbaikan}

Setelah dilakukan analisis dan perbaikan, berikut adalah data checksheet setelah perbaikan: 


\begin{tabular}{|c|c|c|c|c|c|c|c|c|c|c|c|}
\hline \multirow[b]{3}{*}{ BULAN } & \multirow[b]{3}{*}{ 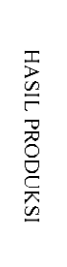 } & \multicolumn{9}{|c|}{ KLASIFIKASI MASALAH } & \multirow{3}{*}{ 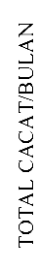 } \\
\hline & & \multicolumn{4}{|c|}{ VISUAL } & \multicolumn{5}{|c|}{ DIMENSI } & \\
\hline & & $\begin{array}{l}\bar{\Xi} \\
\bar{z} \\
\underline{\underline{\pi}} \\
\frac{\pi}{\underline{z}} \\
\bar{\Xi}\end{array}$ & 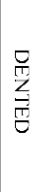 & $\underset{⿱ \pi}{\mathbb{2}}$ & 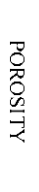 & 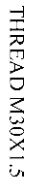 & $\begin{array}{l}z \\
0 \\
\dot{J} \\
+\end{array}$ & 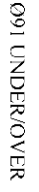 & 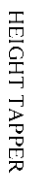 & $\begin{array}{l}z \\
0 \\
0 \\
\Pi \\
3 \\
\bar{Z} \\
\vdots\end{array}$ & \\
\hline Januari & 2852 & 9 & 11 & 0 & 4 & 0 & 2 & 0 & 2 & 18 & 46 \\
\hline Februari & 6235 & 24 & 14 & 0 & 13 & 0 & 20 & 1 & 0 & 10 & 82 \\
\hline Maret & 7044 & 16 & 7 & 0 & 15 & 3 & 16 & 1 & 3 & 11 & 72 \\
\hline April & 4901 & 14 & 10 & 0 & 17 & 0 & 12 & 2 & 0 & 6 & 61 \\
\hline Mei & 4610 & 12 & 3 & 0 & 4 & 0 & 8 & 2 & 1 & 7 & 37 \\
\hline Juni & 4872 & 24 & 10 & 0 & 6 & 0 & 25 & 3 & 0 & 12 & 80 \\
\hline Total & 30514 & 99 & 55 & 0 & 59 & 3 & 83 & 9 & 6 & 64 & 378 \\
\hline
\end{tabular}

Sumber: Hasil Pengolahan Data

Berikut adalah tabel perbandingan hasil produksi dengan produk cacat sebelum dan sesudah perbaikan:

Tabel 4.5. Data Jumlah Perbandingan Produk Cacat Boss Rotor Sebelum dan Sesudah Perbaikan \begin{tabular}{|l|l|l|l|l|l|l|l|l|l|l|l|l|l|}
\hline Tahun 2016 & 1 & 2 & 3 & 4 & 5 & 6 & 7 & 8 & 9 & 10 & 11 & 12 & Total \\
\hline
\end{tabular} \begin{tabular}{|l|c|c|c|c|c|c|c|c|c|c|c|c|c|}
\hline Hasil Produks & 11118 & 5864 & 4469 & 6778 & 10770 & 9193 & 1923 & 8930 & 2475 & 16951 & 9420 & 7709 & 95600 \\
\hline
\end{tabular}

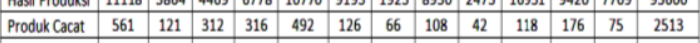

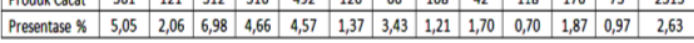

\begin{tabular}{|l|l|l|l|l|l|l|l|l|l|l|l|l|l|}
\hline Tohun 2017 & 1 & 2 & 3 & 4 & 5 & 6 & 7 & 8 & 9 & 10 & 11 & 12 & Total \\
\hline
\end{tabular}

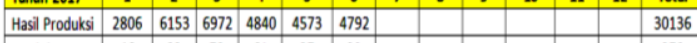

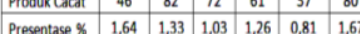

Dari hasil proses sebelum dan sesudah perbaikan diketahui bahwa hasil sebelum perbaikan diketahui yaitu total produksi 95600 pcs dan NG 2513 pcs dengan presentase $2,63 \%$, sedangkan sesudah perbaikan yaitu diketahui total produksi 30136 pcs dan NG 378 dengan presentase $1,25 \%$ artinya ada penurunan setelah dilakukan implementasi perbaikan. Berikut adalah grafik dari semua data perbandingan diatas, sebelum perbaikan dan sesudah perbaikan:

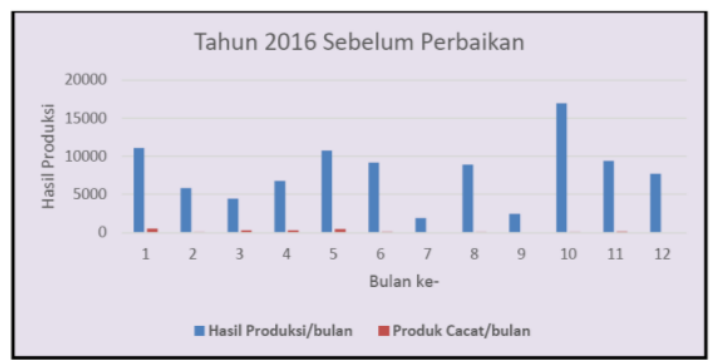

Gambar 4.6. Data Sebelum Perbaikan

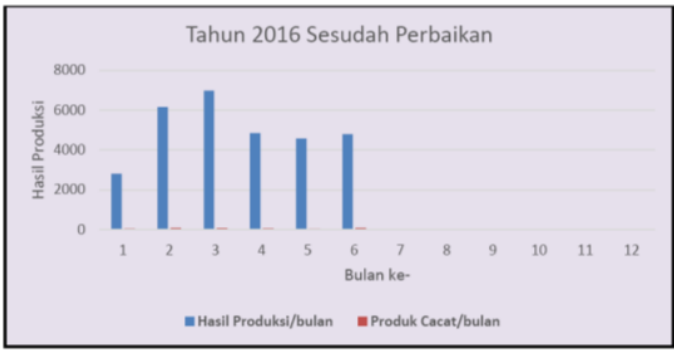

Gambar 4.7. Data Sesudah Perbaikan

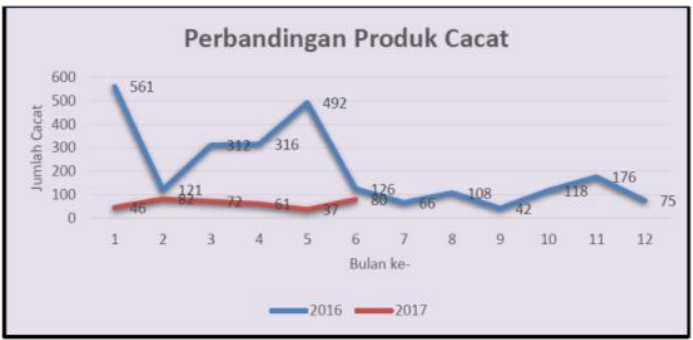

Gambar 4.6. Perbandingan Data Sebelum dan Sesudah Perbaikan

\section{KESIMPULAN DAN SARAN \\ 1. Simpulan}

Berdasarkan dari hasil penelitian produk cacat boss rotor tipe K41A dengan menggunakan metode seven tools, dapat disimpulkan bahwa: Berdasarkan data dari hasil produksi boss rotor tipe $\mathrm{K} 41 \mathrm{~A}$ yang diperoleh dari bulan Januari 2016 sampai dengan bulan Desember 2016 mencapai 95600 pcs. Dari hasil pengolahan data dari grafik diagram pareto ada 4 jenis cacat yang paling dominan atau yang paling besar selama proses produksi yaitu jenis cacat underfill mencapai angka $34,2 \%$ yaitu sebanyak 860 pcs, porositas dengan jumlah produk cacat mencapai angka persentase $15,7 \%$ sebanyak 394 pcs, dented dengan jumlah produk cacat mencapai angka persentase $15,6 \%$ sebanyak 392 pcs, dan produk cacat yang disebabkan oleh setting mesin mencapai angka persentase $12,7 \%$ sebanyak 318 pcs. Dengan menggunakan alat bantu seven tools khususnya pada diagram fishbone akhirnya ditemukan bahwa penyebab cacat yang paling dominan pada produk

\section{Saran}

1. Perusahaan perlu mengadakan training terlebih dahulu kepada karyawan baru supaya karyawan baru tersebut mengenali produk dan setiap tahapan proses produksi;

2. Perlu diadakan training secara periodic terhadap semua karyawan supaya karyawan lebih memperdalam pengetahuan 
tentang proses produksi dan kualitas produk;

3. Departemen Quality harus lebih aktif untuk memberikan edukasi tentang batasan-batasan produk cacat; dan

4. Departemen Engineering harus melakukan Improvement terhadap semua proses produksi yang masih belum maksimal.

\section{DAFTAR PUSTAKA}

Irma Astriyani. 2016. Analisis Pengendalian Kualitas Bahan Baku Acrylic Resin Pada Produk Spray Paint di PT X. Sekolah Tinggi Teknologi Mutu Muhammadiyah. Tangerang

Miftahul Janah. 2017. Analisis Produk Cacat dan Produk Rusak (Studi Pada CV. Aneka Karya Glass Pabelan)

http://eprints.iainsurakarta.ac.id/241/1/5.\%20Miftahul\%20 Janah\%20ok.pdf. Diakses pada tanggal 12 Juli 2017
Moses David Jonathan. 2016. Analisis Pengendalian Kualitas Untuk Mengendalikan Produk Cacat Dengan Menggunakan Seven Tools.

http://eprints.undip.ac.id/48934/1/07_JONAT HAN.pdf. Diakses pada tanggal 12 Juli 2017

Bakhtiar S, Suharto Tahir dan Ria Asysyfa Hasni. 2013. Analisis Pengendalian Kualitas Dengan Menggunakan Metode Statistical Quality Control (SQC).

https://journal.unimal.ac.id

Ade Momon S., Ir, MT. 2012. Implementasi Sistem Pengendalian Kualitas Dengan Metode Seven Tools Terhadap Produk Shotblas Pada Proses Cast Wheel di PT. $X Y Z$.

https://www.unsika.ac.id 